\title{
ESTUDO DE HPAS, NITRO-HPAS E QUINONAS EM AMOSTRAS AMBIENTAIS DO MUNICÍPIO DE ILHÉUS/BA
}

\author{
AUTOR: THAYNA KESLLEY ANDRADE DE ALMEIDA \\ CO-AUTOR/ORIENTADOR: LEILA OLIVEIRA SANTOS
}

\begin{abstract}
Resumo: Muitos são os poluentes encontrados no meio ambiente, dentre eles, os hidrocarbonetos policíclicos aromáticos (HPAs). Hidrocarbonetos policíclicos aromáticos são compostos químicos que possuem em sua fórmula estrutural átomos de carbono e hidrogênio agrupados em anéis aromáticos, oriundos de fontes naturais ou antropogênicas, em sua maior parte, da combustão incompleta de combustíveis fósseis e seus derivados. Dos HPAs, derivam os hidrocarbonetos policíclicos aromáticos oxigenados (HPAO), também chamados de quinonas, e os Nitro-hidrocarbonetos policíclicos aromáticos (nitro-HPAs). A abundância, alta estabilidade química e toxicidade elevada colocaram os hidrocarbonetos policíclicos aromáticos em atenção nas últimas décadas, também devido às suas características mutagênicas e carcinogênicas. As atividades desenvolvidas nas adjacências da região costeira de llhéus, aliadas a proximidade com o porto e o centro urbano, podem estar poluindo os recursos ambientais, tanto a água, como o ar e os sedimentos. Neste trabalho, objetivou-se determinar simultaneamente 32 compostos orgânicos (HPAs, nitro-HPAs e quinonas) em amostras de sedimento por GC-MS presentes em uma área costeira de llhéus-BA. As amostras foram coletadas, liofilizadas, homogeneizadas e então, sonicadas para iniciar a injeção automática. Os limites de quantificação ficaram entre 88,5 e 487,5 ng.g-1 para os HPAs, entre 202,5 e 1317,8 ng.g-1 para as quinonas e entre 450,2 e 2580,8 ng.g-1 para os nitro-HPAs. Foram encontrados 11, dos 32 compostos analisados, dos quais, 5 HPAs: acenafteno, fluoreno, fenantreno, benzo(a) antraceno e o benzo(b)fluoranteno; 5 nitro-HPAs: 1 nitronaftaleno, 2nitronaftaleno, 1 metil5nitronaftaleno, 1 metil6nitronaftaleno e 2nitrofluoreno; e 1 quinona: 1,2 naftoquinona. Por fim, o método utilizado mostrou-se eficaz na determinação dos compostos e os resultados obtidos mostram a necessidade de novos estudos na área, devido às suas características geográficas e ao provável comprometimento da qualidade ambiental.
\end{abstract}

Palavras-chave: HPA, nitro-HPA, oxi-HPA, sedimentos. 